\title{
BMJ Open How patients' experiences of respiratory tract infections affect healthcare-seeking and antibiotic use: insights from a cross- sectional survey in rural Anhui, China
}

\author{
Mengjie Diao, ${ }^{1}$ Xingrong Shen, ${ }^{1}$ Jing Cheng, ${ }^{1}$ Jing Chai, ${ }^{1}$ Rui Feng, ${ }^{2}$ \\ Panpan Zhang, ${ }^{1}$ Rongyao Zhou, ${ }^{1}$ Helen Lambert, ${ }^{3}$ Debin Wang ${ }^{1}$
}

To cite: Diao M, Shen X, Cheng J, et al. How patients' experiences of respiratory tract infections affect healthcare-seeking and antibiotic use: insights from a cross-sectional survey in rural Anhui, China. BMJ Open 2018;8:e019492. doi:10.1136/ bmjopen-2017-019492

- Prepublication history and additional material for this paper are available online. To view these files, please visit the journal online (http://dx.doi org/10.1136/bmjopen-2017019492).

Received 7 September 2017 Revised 19 December 2017 Accepted 4 January 2018
Check for updates

${ }^{1}$ School of Health Service Management, Anhui Medical University, Hefei, Anhui, China ${ }^{2}$ Library Department of Literature Retrieval and Analysis, Anhui Medical University, Hefei, Anhui, China

${ }^{3}$ Department of Population Health Sciences, University of Bristol, Bristol, UK

Correspondence to

Dr Debin Wang;

dbwang@vip.sina.com

\section{ABSTRACT}

Objective To investigate the occurrence of reported respiratory tract infection (RTI) symptoms and their effects on use of self and professional care among patients in the community.

Design A cross-sectional retrospective household survey. Setting 12 administrative villages from rural Anhui, China. Participants 2160 rural adult residents aged $\geq 18$ years registered as rural residents and actually living in the sampled villages when this study was conducted.

Method The respondents were recruited using stratifiedclustered randomised sampling. A structured questionnaire was deployed to solicit information about social demographics, symptoms of last RTI and healthcareseeking following the RTI. Descriptive analyses were performed to investigate the reported symptoms, and multivariate logistic regression models were developed to identify relationships between number of concurrent symptoms and healthcare-seeking and antibiotics use. Results A total of 1968 residents completed the survey, resulting in a response rate of $91.1 \%$. The number of concurrent symptoms showed a clear increasing trend with seeking help from clinics and being prescribed antibiotics. Multivariate regression revealed statistically significant associations between the following: (a) visiting clinics and education $(0 \mathrm{R}=0.790)$, sore throat $(\mathrm{OR}=1.355)$, cough $(\mathrm{OR}=1.492)$, shortness of breath $(\mathrm{OR}=1.707)$ and fever $(\mathrm{OR}=2.142)$; (b) buying medicine from shops without prescription and education $(\mathrm{OR}=1.230)$ and cough $(\mathrm{OR}=1.452)$; (c) getting antibiotics at clinics and sore throat $(\mathrm{OR}=2.05)$ and earache and/or tinnitus $(\mathrm{OR}=4.884)$; and (d) obtaining antibiotics at medicine shops and productive cough $(\mathrm{OR}=1.971)$.

Conclusions Reported RTI symptoms play an important role in shaping both patient- and doctor-led responses.

\section{BACKGROUND}

Respiratory tract infections (RTIs) are the most common diseases in humans. Studies have demonstrated that adults usually experience one to three episodes of upper RTI per year. ${ }^{12}$ RTIs claim over 3 million lives annually and are the leading cause of death for children under 5 years. ${ }^{34}$ Although many RTIs

\section{Strengths and limitations of this study}

- This study demonstrates relationships between patient-reported symptoms and respiratory tract infection (RTI)-related healthcare-seeking.

- The study is the first to describe the collective effects of concurrent symptoms as perceived by patients experiencing them.

- The study relies on subjective retrospective perceptions or self-reports and therefore may be biased by potential under-reporting or over-reporting and recall bias.

- The study used a broad definition of RTIs, and the occurrence of symptoms may be distorted by seasonal and other variations when the study was conducted.

are mild and self-limiting, they are associated with a significant burden in terms of medical visits as well as work and school absenteeism. ${ }^{56}$ The median duration of an episode of non-influenza-related viral RTI (the most common but least serious kind of RTIs) is estimated to be 7.4 days, with $25 \%$ of cases lasting for 2 weeks. ${ }^{7}$ In addition to the heavy burden on patients and health systems, RTIs are closely linked to antibiotic use, and hence the development of antibiotic resistance. RTIs account for up to $60 \%$ of all antibiotic prescribing in UK primary care. ${ }^{8}$ Excessive use of antibiotics is recognised as one of the most serious public health issues worldwide. ${ }^{10}$

According to the 10th edition of the International Classification of Diseases, RTIs comprise as many as 34 kinds of infections. However, their symptoms are relatively limited, consisting mainly of sore throat, fever, cough, productive cough, rhinorrhoea with or without pus, shortness of breath, headache and/or general discomfort, earache and/or tinnitus. ${ }^{11} 12$ When faced with symptoms, patients' responses vary greatly. 
Some patients manage their symptoms by simply resting, drinking warm water, and so on, without using any medicines $^{13}$; others buy medicines from medicine shops or pharmacies or seek professional help from doctors ${ }^{14-16}$; still others opt for traditional remedies. ${ }^{17} 18$ A 2014 study of consumer attitudes on cough and cold in USA indicated that $36.1 \%$ of those surveyed reported beginning over-the-counter (OTC) treatment at the first sign of a cough or cold, $42.6 \%$ waited until cold symptoms 'get bad enough' (ie, to cause distress) and another $20.2 \%$ waited until they had more than one symptom before beginning treatment. Altogether, 55\% sought professional care eventually. ${ }^{19}$ These varied responses have been attributed to a wide range of reasons including: features of the disease, such as severity of symptoms and their patterns of progression ${ }^{2}$; 'demand side' issues such as age, gender, education, ${ }^{20}$ knowledge and attitudes about RTIs and RTI-related services, ${ }^{21-25}$ cultural expectations and social norms ${ }^{2627}$; and 'supply side' factors such as perverse financial incentives, systemic pressures on healthcare providers and professional standards. ${ }^{26} 2829$

RTIs are very common in China with an incidence rate ranging from $84.13 \%$ to $120.83 \%$ in $2006 .^{30}$ This translates to $1.16-1.67$ billion person-times of RTIs annually in the whole country. Data about service use for RTIs among China residents are scarce, but the limited research available reports huge discrepancies between different populations and very high use of antibiotics in various medical settings. An earlier study in rural primary care settings of 10 provinces in Western China found that nearly $50 \%$ of patients were prescribed antibiotics. ${ }^{31}$ Another recent study found that antibiotics were prescribed for $78 \%$ of colds and $93.5 \%$ of acute bronchitis cases. ${ }^{32}$ According to our systemic literature review, few studies focus on factors affecting service and antibiotics use for RTIs or investigate reasons for variations in service use and antibiotic prescribing for RTIs in China. Although a number of papers on reasons for health service utilisation in general did include RTIs as a subcomponent, they addressed only demand and supply side factors, with little attention being paid to RTI symptoms among patients in the community and their effects on decisions about self or professional care. This study aims to investigate reported RTI symptoms and their effects on use of self and professional care among patients in the community.

\section{METHODS}

\section{Sites and population}

The study used a retrospective cross-sectional household survey design and adopted a stratified-clustered randomised sampling approach in recruiting site villages and participating residents. Selection of site villages proceeded in four steps. Step 1 divided all counties in Anhui province into north, middle and south regions. Step 2 randomly selected four counties from each of the three regions and one township from each of the counties selected, and then one administrative village from each of the site townships selected above. Step 3 randomly selected one household from the village selected as the starting household and then recruited 180 households that were geographically closest to the starting household. Step 4 randomly selected one household member from each of these households according to preset eligibility criteria, that is, men and women who were aged 18 years and over were registered as rural residents and were actually living in the sampled villages when this study was conducted, and were willing and able to participate in the survey.

\section{Questionnaire}

The study used a structured questionnaire consisting of questions about four categories of variables: (a) social demographics (eg, gender, age and education); (b) last episode of symptomatic RTI, including symptoms experienced; (c) responses to the RTI, including taking leftover medicines, buying any type of medicine OTC from medicine shops (hereafter referred to as buying medicine) and seeking treatment from clinics; (d) antibiotics obtained from clinics and medicine shops. In China, a pharmacy generally refers to a department within a hospital or clinic that dispenses medicines to patients according to prescriptions by the clinicians working for the same hospital/clinic, while a medicine shop is an independent business that sells medicines to customers with or without prescriptions from clinicians. 'Seeking help from clinics' refers to visiting a local health facility staffed by a qualified health professional and is thus largely equivalent to 'seeking professional care' in western countries. Conversely, the use of antibiotics does not necessarily mean that professional care was sought. Antibiotics may be purchased from medicine shops directly without prescription or kept at home for subsequent use. Almost all medicine shops in China sell both OTC and non-OTC medicines, including antibiotics. Although they may be displayed in separate cabinets, in practice non-OTC medicines may be purchased directly without prescription and customers generally do not distinguish these two types of medicines.

\section{Data collection}

Field data collection took place from 30 April 2016 to 12 May 2016 via face-to-face interviews using the structured questionnaire. Twenty-six undergraduate students from Anhui Medical University performed the interviews. Measures taken to ensure data quality included (a) training and examination of the data collectors; (b) daily checks by a quality control supervisor of all questionnaires completed each day; (c) retest of 5\% randomly selected subjects; (d) feedback of errors found via daily checks and readministering of the questionnaire; (e) elimination of disqualified field data collectors.

\section{Data analysis}

Data were double-entered using EPI DATA V.3.1, and SPSS V.10.01 and Microsoft Excel 2010 were used to 


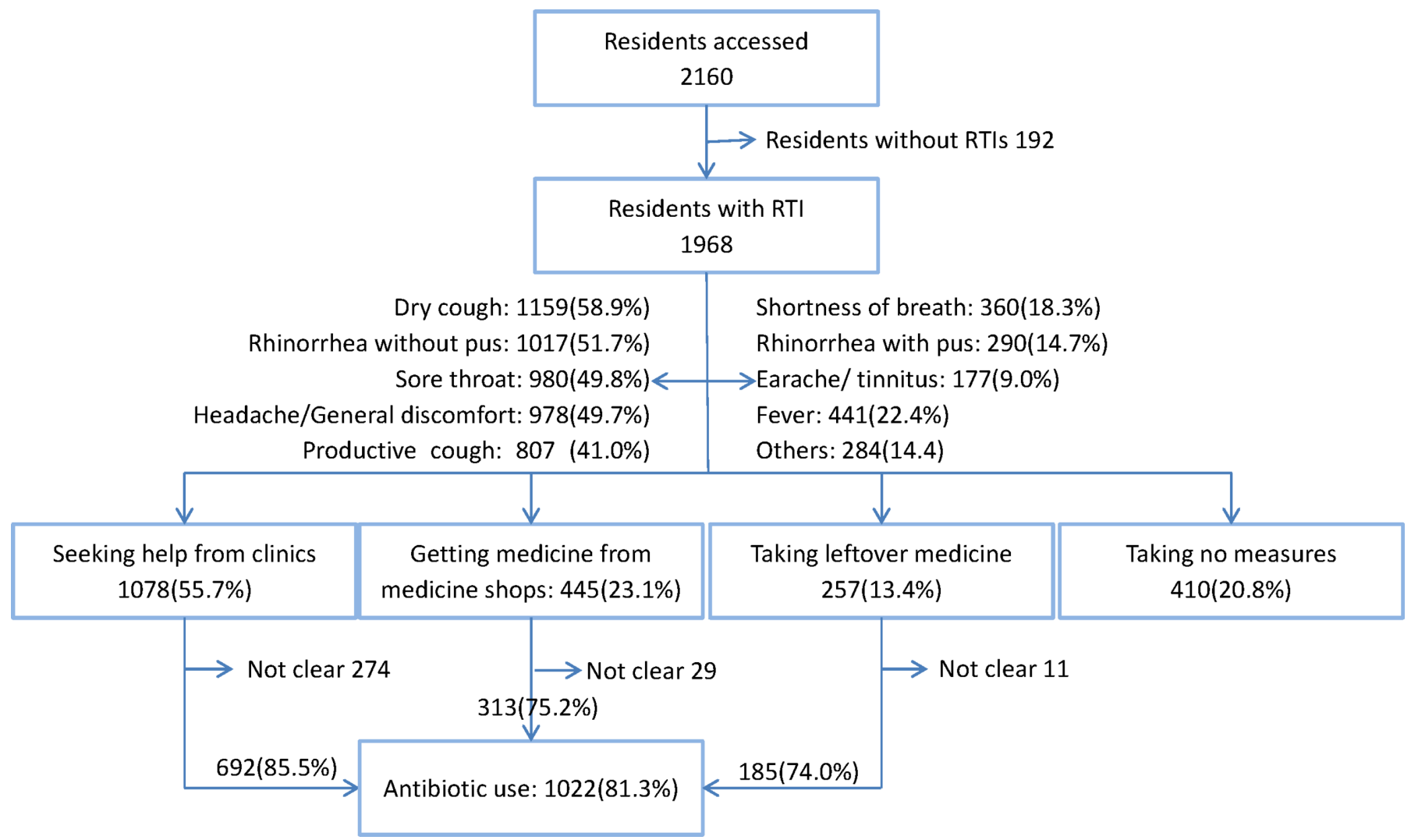

Figure 1 Flow chart describing symptoms, healthcare-seeking and antibiotics use among study population. RTI, respiratory tract infection.

analyse the data. Data analysis included (a) distribution of respondents by gender, age and education; (b) multivariate logistic regression of healthcare-seeking and antibiotics use using social demographics and common symptoms as the independent variables; (c) relationships between number of symptoms experienced by a single patient and his or her healthcare-seeking and antibiotics use. Cases with missing data were excluded from the data analyses.

Participation of rural residents was voluntary, and written informed consent was obtained from all participants.

\section{RESULTS}

Overview of participants, symptoms and healthcare-seeking

As shown in figure 1 and table 1, a total of 2160 residents were accessed and 1968 completed the survey, resulting in a response rate of $91.1 \%$. The mean age of respondents was 50.39 years ( $\mathrm{SD}=13.04$ years). The majority $(68.0 \%)$ were females and around one-third $(29.6 \%)$ had no formal school education. The high proportion of female respondents in this random sample results from the fact that in this rural area the majority of male residents have moved to cities to obtain temporary work. ${ }^{33}$ Over $80 \%$ of reported infections had occurred within 9 months prior to the survey. Dry cough $(58.9 \%, 1159)$, rhinorrhoea without pus $(51.7 \%, 1017)$ and sore throat $(49.8 \%, 980)$ were the most common symptoms. $55.7 \%$ of respondents reported seeking professional help from clinics, $13.4 \%$ bought medicine from medicine shops, 23.1\% used leftover medicine from previous illnesses and 20.8\% did nothing. Altogether, $81.3 \%$ of respondents reported having used antibiotics to treat their RTI. As shown in table 2, time interval between onset of infection and when the data were collected was not associated with any statistical differences in healthcare-seeking behaviour except use of leftover medicines, suggesting that recall bias had limited effects (see also the Discussion and Study limitations sections).

\begin{tabular}{lcll}
\hline $\begin{array}{l}\text { Table 1 Characteristics of } 1968 \text { adults with respiratory } \\
\text { tract infection }\end{array}$ & Male (\%) & Female (\%) & Total (\%) \\
\hline \multicolumn{5}{c}{ (years) } \\
\hline Age (y & $128(20.3)$ & $317(23.7)$ & $445(22.6)$ \\
$18-40$ & $152(24.1)$ & $360(26.9)$ & $512(26.0)$ \\
$41-50$ & $134(21.3)$ & $323(24.1)$ & $457(23.3)$ \\
$51-60$ & $216(34.3)$ & $338(25.3)$ & $554(28.2)$ \\
$\geq 61$ & $95(15.1)$ & $487(36.4)$ & $582(29.6)$ \\
\hline Education (years) & $195(31.0)$ & $390(29.1)$ & $585(29.7)$ \\
\hline 0 & $269(42.7)$ & $360(26.9)$ & $629(32.0)$ \\
\hline $1-6$ & $71(11.3)$ & $101(7.5)$ & $172(8.7)$ \\
$7-9$ & 630 & 1338 & 1968 \\
\hline 10 & & & \\
\hline Total &
\end{tabular}


Table 2 Service use by time interval between onset of infection and data collection

\begin{tabular}{lllllll}
\hline $\begin{array}{l}\text { Time interval } \\
\text { (days) }\end{array}$ & Total & $\begin{array}{l}\text { Buying medicine } \\
\text { from medicine } \\
\text { shops }\end{array}$ & $\begin{array}{l}\text { Taking leftover } \\
\text { medicine }\end{array}$ & $\begin{array}{l}\text { Seeking help } \\
\text { from clinics }\end{array}$ & $\begin{array}{l}\text { Getting } \\
\text { antibiotics at } \\
\text { clinics }\end{array}$ & $\begin{array}{l}\text { Getting } \\
\text { antibiotics at } \\
\text { medicine shops }\end{array}$ \\
\hline$\leq 90$ & $844(44.6 \%)$ & $196(23.3 \%)$ & $136(16.2 \%)$ & $475(56.3 \%)$ & $315(86.1 \%)$ & $144(77.4 \%)$ \\
$91-180$ & $494(26.1 \%)$ & $107(21.8 \%)$ & $60(12.2 \%)$ & $276(55.9 \%)$ & $177(85.9 \%)$ & $67(67.0 \%)$ \\
$181-270$ & $192(10.2 \%)$ & $51(26.6 \%)$ & $18(9.4 \%)$ & $110(57.3 \%)$ & $72(85.7 \%)$ & $38(80.9 \%)$ \\
$\geq 271$ & $361(19.1 \%)$ & $80(22.2 \%)$ & $34(9.6 \%)$ & $198(54.8 \%)$ & $116(84.7 \%)$ & $59(78.7 \%)$ \\
$\chi^{2}$ & & 1.907 & 13.438 & 0.355 & 0.165 & 5.409 \\
\hline value & & 0.592 & 0.004 & 0.949 & 0.983 & 0.144 \\
\hline
\end{tabular}

Bold $\mathrm{P}$ value, below the significant level of 0.05 .

\section{Individual symptoms and treatment-seeking}

Table 3 displays logistic regression modelling between service use and individual symptoms and sociodemographic characteristics. Education was negatively associated with seeking help from clinics $(\mathrm{OR}=0.790(0.697$ to 0.896$))$, but positively related with buying medicine $(\mathrm{OR}=1.230$ (1.068 to 1.417$)$ ) and using leftover medicine $(\mathrm{OR}=1.283$ (1.073 to 1.535$))$. Females were more likely to use leftover medicine than males $(\mathrm{OR}=2.016(1.411$ to 2.881$))$, while age had no effects on any treatment-seeking behaviour. When controlled for social demographic characteristics, buying medicine was positively related with cough $(\mathrm{OR}=1.452$ (1.124 to 1.875$))$; taking leftover medicine, with headache and soreness $(\mathrm{OR}=1.581$ (1.169 to 2.138)); and seeking help from clinics, with sore throat $(\mathrm{OR}=1.355$ (1.109 to 1.654$))$, cough $(\mathrm{OR}=1.492 \quad(1.198$ to 1.859$))$, shortness of breath $(\mathrm{OR}=1.707 \quad(1.287$ to 2.265)) and fever $(\mathrm{OR}=2.142$ (1.654 to 2.775) ). Being prescribed antibiotics at clinics was related positively only to earache and/or tinnitus $(\mathrm{OR}=4.884$ (1.162 to 20.522)), while purchasing antibiotics OTC from medicine shops was positively linked with productive cough $(\mathrm{OR}=1.971$ (1.125 to 3.453$))$. Rhinorrhoea with or without pus is not associated with any specific treatment-seeking behaviour.

\section{Concurrent symptoms and service use}

Figure 2 and online supplementary appendices 1 and 2 display the relationships between service-seeking and number of concurrent symptoms in total and by demographic characteristics. Overall, seeking help from clinics and getting antibiotics at clinics show a clear increasing trend with number of symptoms. Only $37.5 \%$ of respondents who had experienced one symptom had sought help from a clinic, while $75.0 \%$ of those who had experienced over seven symptoms had done so. Similarly, the use of antibiotics at clinics increased from $77.7 \%$ for patients with one symptom to $96.4 \%$ for those with over seven symptoms. However, buying medicine from shops, taking leftover medicine and getting antibiotics from shops showed no statistically significant trend as the number of symptoms increased. The relationships between number of symptoms and service-seeking were consistent across all gender, age and education subgroups. This intersubgroup consistency was also observed in the null trend of getting antibiotics at clinics or at medicine shops by patients with increasing number of symptoms.

\section{DISCUSSION}

This study has uncovered useful data for better understanding the experience of RTIs among patients in the community and their relations with healthcare-seeking and antibiotics use. The study showed selective associations between service use and sociodemographic characteristics. Education was negatively related to seeking help from clinics but positively associated with taking leftover medicine and buying medicine from shops; while females are more likely than males to take leftover medicine. However, specifically using antibiotics obtained from clinics and medicine shops did not show any statistically significant sociodemographic differences. These findings may suggest that decisions on whether or not to visit a clinic, take leftover medicine or buy medicine from a shop are made by patients themselves and are thus amenable to the influence of patients' sociodemographic characteristics, while the decision on whether or not to provide antibiotics to patients is determined mainly by the doctors at clinics or staff at medicine shops and thus is not affected by these characteristics.

The study documented strong and consistent relations between symptoms and service-seeking. As the number of concurrent symptoms increased from 1 to 7 or more, the proportion of patients who had sought help from clinics increased from $37.5 \%$ to $75.0 \%$, and the proportion of service seekers who had been prescribed antibiotics increased from $77.7 \%$ to $96.4 \%$. These findings suggest that clustering of symptoms affects both patient- and doctor-led behaviour and thus merits particular attention in future interventions. Interestingly, the difference in the percentage of service-seeking for patients with one symptom $(37.5 \%)$ versus that for those with over seven symptoms $(75.0 \%)$ is substantially greater than that of antibiotics prescribing $(77.7 \%$ vs $96.4 \%)$. One possible explanation for this difference is that patients directly suffer from symptoms, while professionals are only told about them by their patients, so patient-led behaviours 


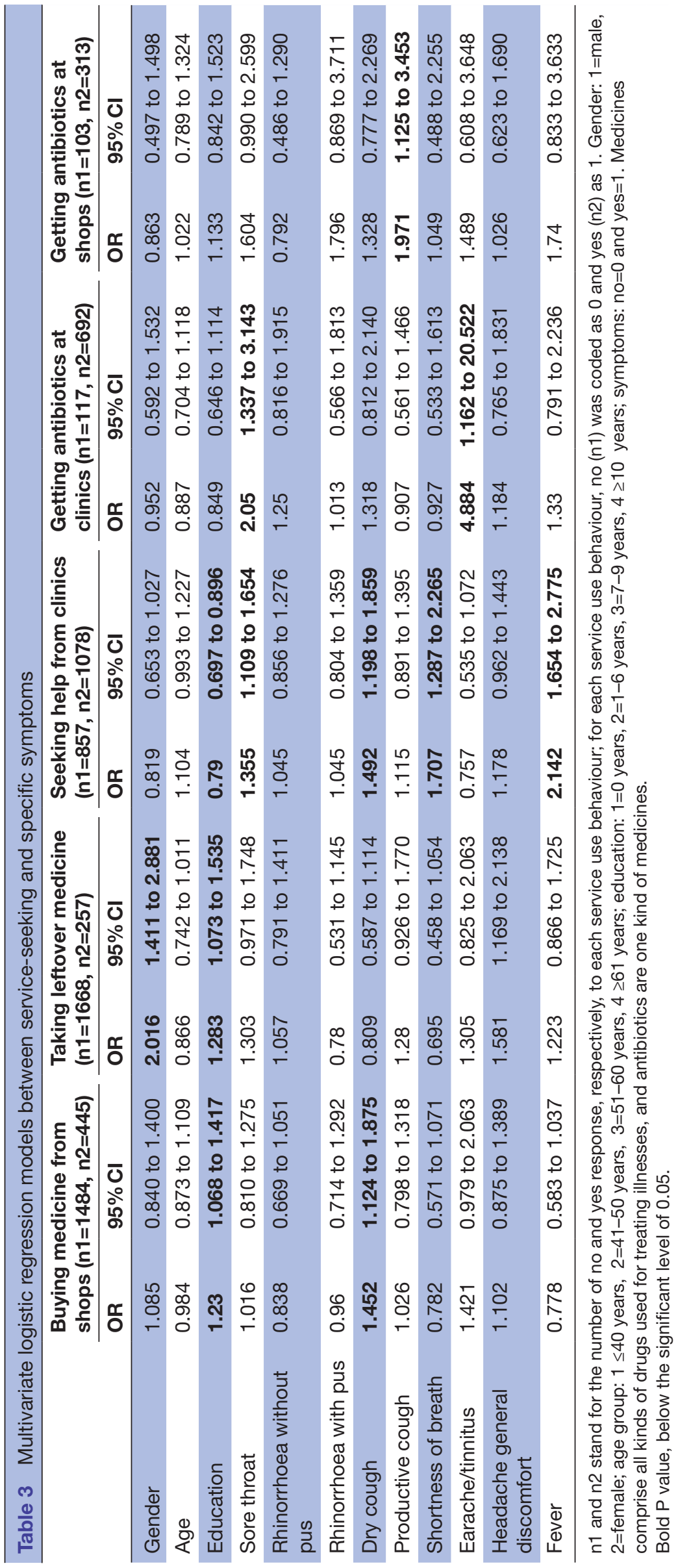




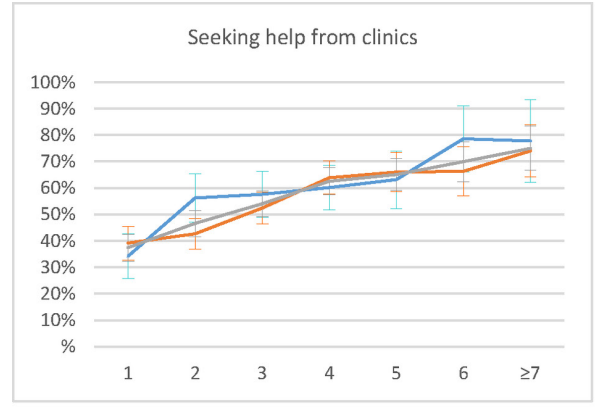

Taking no measures

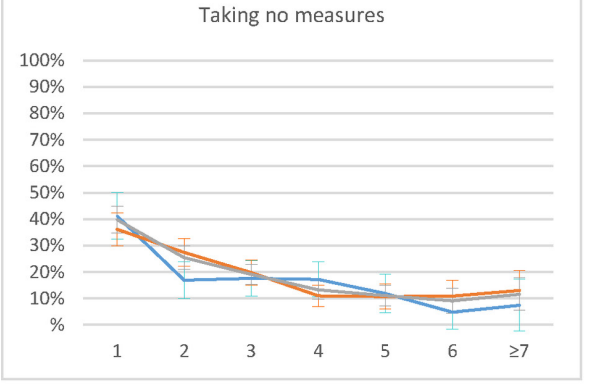

Getting medicine from medicine shops

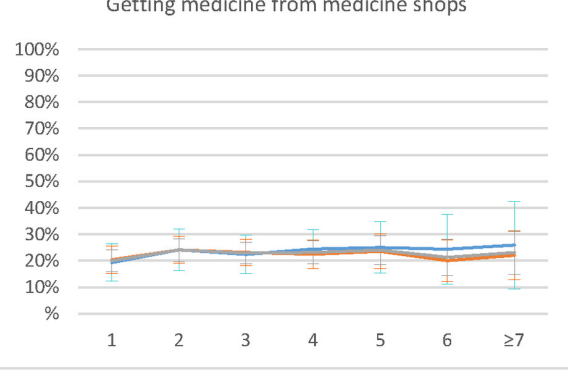

Getting antibiotics at clinics

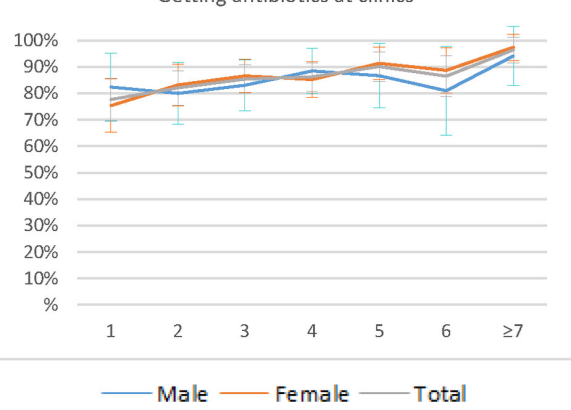

Taking left over medicine

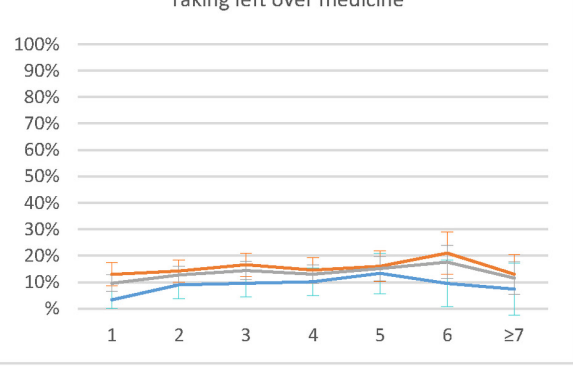

Getting antibiotics at medicine shops

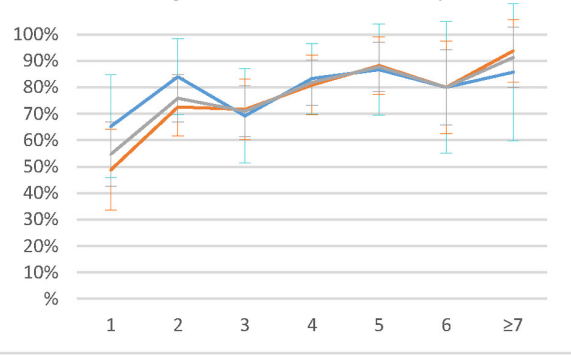

Figure 2 Service-seeking by number of symptoms in total and by genders.

(ie, health service-seeking) may be more sensitive to symptoms than professional-led ones (ie, antibiotics prescribing). ${ }^{3435}$ In addition, as lay persons, patients may not be as capable as doctors of distinguishing important from non-important symptoms, and so numbers of symptoms have closer links with perceptions of acute or serious illness among patients than among health professionals. As for the lack of correlation between number of symptoms and purchase of medicines from shops, this may reflect the combined effects of two drivers. On one hand, more symptoms serve as a greater driver for patients to seek professional help from clinics as well as medicine shops. On the other hand, seeking help from clinics and shops are competitive behaviours and as patients experience more symptoms they are more likely to visit clinics than shops.

In addition, positive relationships were found between a number of specific symptoms and service-seeking. Seeking help from clinics was linked to, in order of magnitude of logistic regression coefficient, fever $(B=0.76)$, shortness of breath $(B=0.54)$, cough $(B=0.40)$ and soreness $(B=0.30)$. These coefficients and their rank order reveal useful information about the perceived importance, suffering and urgency of each of the corresponding symptoms for patients. Compared with seeking help from clinics, the driving symptoms for buying medicine from shops may be milder in nature and fewer in number, with only one symptom, dry cough, being positively associated with the latter behaviour. This indicates that patients with equal access to the two kinds of help tend to choose clinics rather than shops if they have more and severer symptoms and vice versa. In addition, being given antibiotics at clinics was linked with earache and/or tinnitus and at medicine shops, with productive cough. These findings are consistent with published evidence. $^{35}$

\section{Study limitations}

The study has a number of limitations. First, it relied on subjective perceptions and self-reports. Individuals are poor at accurately reporting certain health behaviours and feelings and inherent tendencies to respond in ways that make them appear healthier or otherwise conform to social norms may introduce bias. However, these characteristics are typically apparent across the board, reducing the effects of this threat to internal validity. More importantly, the long recall period between last experienced episode and survey data collection is likely to have led to recall bias; milder RTIs in particular, exact patterns of symptom experience and details of associated treatment-seeking behaviour may have been forgotten. Our findings do suggest some extent of recall/memory bias, but table 1 shows that there was no statistical relationship between time interval from onset of infection and data collection for any healthcare-seeking behaviour except for use of leftover medicines, which was reported as $9.6 \%$ among patients with a time interval of over 9 months compared with $16.2 \%$ among patients with a less than 3-month time interval. Second, given the broad symptom-based definition of RTIs used in the study, seasonal and other influences on symptom occurrence may have affected the frequency of symptoms. Third, the over-representation of females may raise concerns about selection biases. However, our analysis revealed no significant differences by gender in terms of symptom-related treatment-seeking except for taking leftover medicines, which was more commonly reported by females. 
Contributors MD participated in data collection and drafted the manuscript. XS and RF designed the instruments and performed data analysis. JChe and JCha implemented field data collection, trained data collectors and controlled data quality. RZ and PZ implemented the data collection. DW provided expertise for overall design of the study and revised and finalised the manuscript. HL contributed to the interpretation of data and revised and finalised the manuscript. All authors approved the final version to be published and agree to be accountable for all aspects of the work in ensuring that questions related to the accuracy or integrity of any part of the work are appropriately investigated and resolved.

Funding This study was supported partly by China-UK Prosperity Fund (grant number PPYCHN1590/15SS19) and partly by the National Natural Science Foundation of China and the Medical Research Council of the UK (grant numbers 81661138001 and 71704003 )

Competing interests None declared.

Patient consent Obtained.

Ethics approval The study protocol was reviewed and approved by the Biomedical Ethics Committee of Anhui Medical University (reference number: 201500800) prior to the study commencing.

Provenance and peer review Not commissioned; externally peer reviewed.

Data sharing statement Anonymised participant data used in the preparation of this article will be made available on request to the lead author.

Open Access This is an Open Access article distributed in accordance with the Creative Commons Attribution Non Commercial (CC BY-NC 4.0) license, which permits others to distribute, remix, adapt, build upon this work non-commercially, and license their derivative works on different terms, provided the original work is properly cited and the use is non-commercial. See: http://creativecommons.org/ licenses/by-nc/4.0/

(c) Article author(s) (or their employer(s) unless otherwise stated in the text of the article) 2018. All rights reserved. No commercial use is permitted unless otherwise expressly granted.

\section{REFERENCES}

1. Leder K, Sinclair MI, Mitakakis TZ, et al. A community-based study of respiratory episodes in Melbourne, Australia. Aust N Z J Public Health 2003;27:399-404.

2. Hull JD, Barton IP, Torgersen J, et al. A survey of the experience and impact of acute upper respiratory tract infections on people in six countries in the $2011 / 2012$ common cold and flu season. Open Journal of Respiratory Diseases 2013;03:175-87.

3. GBD 2013 Mortality and Causes of Death Collaborators. Global, regional, and national age-sex specific all-cause and causespecific mortality for 240 causes of death, 1990-2013: a systematic analysis for the Global Burden of Disease Study 2013. Lancet 2015;385:117-71.

4. WHO. More than 1.2 million adolescents die every year, nearly all preventable. http://www.who.int/mediacentre/news/releases/2017/ yearly-adolescent-deaths/en/ (accessed 5 Jul 2017).

5. Adam PF, Hendershot GE, Marano MA. Current estimates from the National Health Interview Survey. Vital Health Stat 1999;10:59-66.

6. Oppong R, Coast J, Hood K, et al. Resource use and costs of treating acute cough/lower respiratory tract infections in 13 European countries: results and challenges. Eur J Health Econ 2011;12:319-29.

7. Thompson M, Vodicka TA, Blair PS, et al. Duration of symptoms of respiratory tract infections in children: systematic review. BMJ 2013;347:f7027.

8. Petersen I, Hayward AC. SACAR Surveillance Subgroup. Antibacterial prescribing in primary care. J Antimicrob Chemother 2007;60(Suppl 1):i43-7.

9. Gulliford MC, Dregan A, Moore MV, et al. Continued high rates of antibiotic prescribing to adults with respiratory tract infection: survey of 568 UK general practices. BMJ Open 2014;4:e006245

10. Costelloe $C$, Metcalfe $C$, Lovering $A$, et al. Effect of antibiotic prescribing in primary care on antimicrobial resistance in individual patients: systematic review and meta-analysis. BMJ 2010;340:c2096-1120.

11. Lu Y, Tong J, Pei F, et al. Viral aetiology in adults with acute upper respiratory tract infection in Jinan, Northern China. Clin Dev Immunol 2013;2013:869521-7.
12. Fischer T, Fischer S, Kochen MM, et al. Influence of patient symptoms and physical findings on general practitioners' treatment of respiratory tract infections: a direct observation study. BMC Fam Pract 2005;6:1-7.

13. Halvorsen PA, Godycki-Cwirko M, Wennevold K, et al. Would GPs advise patients with respiratory tract infections to refrain from exercise, stay indoors or stay in bed? Survey of GPs in Poland and Norway. Eur J Gen Pract 2014;20:209-13.

14. Ahmad A, Patel I, Mohanta GP, et al. Evaluation of self medication practices in rural area of town Sahaswan at Northern India. Ann Med Health Sci Res 2014;4:73-8.

15. Courtenay M, Rowbotham S, Lim R, et al. Antibiotics for acute respiratory tract infections: a mixed-methods study of patient experiences of non-medical prescriber management. BMJ Open 2017; 7:e013515.

16. Essack S, Pignatari AC. A framework for the non-antibiotic management of upper respiratory tract infections: towards a global change in antibiotic resistance. Int J Clin Pract Suppl 2013;67:4-9.

17. Wang X, Liu Z. Prevention and treatment of viral respiratory infections by traditional Chinese herbs. Chin Med J 2014;127:1344-50.

18. Wun YT, Lam TP, Lam KF, et al. Comparison of the knowledge, attitudes and practice with antibiotic use between traditional Chinese medicine and western medicine usual attenders in Hong Kong. Complement Ther Med 2014;22:99-106.

19. Blaiss MS, Dicpinigaitis PV, Eccles R, et al. Consumer attitudes on cough and cold: US (ACHOO) survey results. Curr Med Res Opin 2015;31:1527-38.

20. Birk HO, Gut R, Henriksen LO. Patients' experience of choosing an outpatient clinic in one county in Denmark: results of a patient survey. BMC Health Serv Res 2011;11:262.

21. Kaae S, Malaj A, Hoxha I. Antibiotic knowledge, attitudes and behaviours of Albanian health care professionals and patients - a qualitative interview study. J Pharm Policy Pract 2017;10:13.

22. Hawking MK, Lecky DM, Touboul Lundgren $P$, et al. Attitudes and behaviours of adolescents towards antibiotics and self-care for respiratory tract infections: a qualitative study. BMJ Open 2017; 7:e015308.

23. Rebnord IK, Sandvik H, Mjelle AB, et al. Factors predicting antibiotic prescription and referral to hospital for children with respiratory symptoms: secondary analysis of a randomised controlled study at out-of-hours services in primary care. BMJ Open 2017;7:e012992.

24. Rebnord IK, Sandvik H, Mjelle AB, et al. Out-of-hours antibiotic prescription after screening with $C$ reactive protein: a randomised controlled study. BMJ Open 2016;6:e011231.

25. Hopkins S. Cultural and socioeconomic determinants of antibiotic use $[\mathrm{m}] / /$ antibiotic policies: fighting resistance. USA: Springer, 2008:29-40.

26. Gach $\mathrm{O}$, Troisfontaines $\mathrm{P}$, Legrand V. Identification of cultural determinants of antibiotic use cited in primary care in Europe: a mixed research synthesis study of integrated design "Culture is all around us". Bmc Public Health 2015;15:1-9.

27. Reynolds L, McKee M. Factors influencing antibiotic prescribing in China: an exploratory analysis. Health Policy 2009;90:32-.

28. Cho HJ, Hong SJ, Park S. Knowledge and beliefs of primary care physicians, pharmacists, and parents on antibiotic use for the pediatric common cold. Soc Sci Med 2004;58:623-9.

29. Ning RG, Min K, Zhen HZ. Analysis of the incidence and treatment of common cold in Guangzhou residents in 2006. Southern China Prev Med 2008;34:46-8.

30. Dong L, Yan H, Wang D. Antibiotic prescribing patterns in village health clinics across 10 provinces of Western China. J Antimicrob Chemother 2008;62:410-5.

31. Wang J, Wang $P$, Wang $X$, et al. Use and prescription of antibiotics in primary health care settings in China. JAMA Intern Med 2014;174:1914-20.

32. Chai J, Chen P, Feng R, et al. Life events and chronic physical conditions among left-behind farmers in rural China a cross-sectional study. BMC Public Health 2015;15:594.

33. Tan YS, Hong CY, Chong PN, et al. Knowledge that upper respiratory tract infection resolves on its own is associated with more appropriate health-seeking behaviour and antibiotic cognition. Singapore Med J 2006;47:518-24.

34. Grigoryan L, Burgerhof JG, Haaijer-Ruskamp FM, et al. Is selfmedication with antibiotics in Europe driven by prescribed use? $\mathrm{J}$ Antimicrob Chemother 2007;59:152-6.

35. Chang AB, Oppenheimer JJ, Weinberger M, et al. Children with chronic wet or productive cough--treatment and investigations: a systematic review. Chest 2016;149:120-42. 